See discussions, stats, and author profiles for this publication at: https://www.researchgate.net/publication/298417401

\title{
Optical Investigation of Ignition Timing and Equivalence Ratio in Dual-Fuel CNG/Diesel Combustion
}

Conference Paper · April 2016

Dol: 10.4271/2016-01-0772

CITATIONS

6

6 authors, including:

2. Julien Apeloig

CORIA

12 PUBLICATIONS 47 CITATIONS

SEE PROFILE

Frederic Grisch

CORIA

125 PUBLICATIONS 1,195 CITATIONS

SEE PROFILE

Some of the authors of this publication are also working on these related projects:

Project CARS and LIF View project

Project Instrumentation development View project
READS

292

Erwan Salaün

CORIA

9 PUBLICATIONS 17 CITATIONS

SEE PROFILE

Charles-Edouard Yvonnet

CERTAM

2 PUBLICATIONS 8 CITATIONS

SEE PROFILE 


\title{
Optical Investigation of Ignition Timing and Equivalence Ratio in Dual-Fuel CNG/Diesel Combustion
}

\author{
Erwan Salaun, Julien Apeloig and Frédéric Grisch \\ CORIA - UMR6614 - Normandie Université
}

\author{
Charles-Edouard Yvonnet, Baptiste Nicolas and Frédéric Dionnet \\ CERTAM
}

\begin{abstract}
Dual-fuel engines are recognized as a short-medium term solution to reduce fuel consumption and pollutant emissions of $\mathrm{CI}$ engines, while maintaining high energy efficiency. Methane $\left(\mathrm{CH}_{4}\right)$ was chosen as it offers the best compromise between its heating value and $\mathrm{H} / \mathrm{C}$ ratio. The high auto-ignition temperature of $\mathrm{CH}_{4}$ requires auto-igniting a small quantity of liquid diesel before it initiates the combustion of the mixture. Therefore, new engine operations need to be specifically developed. This investigation explores the impact of time sequences of injection of the liquid fuel on the ignition of homogenous methane/air mixture. Experiments were performed on a Rapid Compression Expansion Machine (RCEM), to reproduce the operating and dynamic conditions encountered in a diesel engine cycle, allowing visualizations of fuel injection and combustion processes through a transparent piston. For the purpose of this work, the RCEM was modified to operate under dual-fuel conditions, while controlling the amount of diesel and methane-gas fueled.

Experiments were performed for a wide range of equivalence ratios of the premixed charge. The study of the liquid fuel penetration and its consequence on igniting the homogenous charge was achieved using high-speed optical diagnostics. High-speed Schlieren technique $(\sim 22 \mathrm{kHz})$ was applied to characterize the diesel spray penetration, as well as the in-cylinder liquid fuel distribution. High-speed shadowgraphy and $\mathrm{OH}^{*}$-chemiluminescence techniques were used to determine ignitions delays. Moreover, the latest diagnostic was used to analyze the flame structure propagation and the heat release evolution.
\end{abstract}

\section{Introduction}

Over the last decades, the development of modern design of compression-ignition engines has largely evolved to enhance higher output efficiencies, greater specific-power outputs, increased reliability and reduction of pollutant emissions. There is an increased need, whether for environmental, economical, or resource preservation reasons, to operate natural or renewable energy sources. Compared to conventional diesel engines, which is characterized by a high efficiency but a high level of soot particles production, and compared to premixed charge gasoline engines, limited by low efficiencies induced by knocking constraints and pumping losses, gas-fueled diesel engines present higher efficiencies thanks to the reduction of pumping losses and heat transfer [1-10]. Additionally, the use of low-cetane gaseous fuels such as Compressed Natural Gas (CNG) or methane offers attractive properties in regard to their higher octane number giving higher resistance to knock and to their short carbon chains allowing a systematic reduction in the particulate matter and the NOx emissions [1,5-6]. On the contrary, their use in diesel engines requires a high-energy source such as spark plug or

Page 1 of 11 pilot-fuel injection to achieve ignition. Previous studies reported in literature reveal that the second solution, defined as dual-fuel combustion operation mode with pilot injection of liquid fuel as igniter is particularly promising. Additionally, the technological conversion of a diesel engine operating in a dual-fuel combustion mode requires few modifications to existing hardware and offers the advantage to switch back to conventional diesel operating mode in case of shortfall in gas supply.

In a general manner, dual-fuel combustion can be considered as made of three main overlapping phenomena: injection [11-14] and ignition of the pilot diesel-fuel [1], ignition of the fuel-to-air mixture in the vicinity of the pilot spray and combustion of the remainder of the primary fuel-to-air mixture by flame propagation [15-16]. Efforts to interpret these complex phenomena need to be supported by a profound understanding of the relevant physical and chemical parameters in order to draw conclusions about the underlying coupled processes governing dual-fuel combustion. In this sense, various studies have previously been conducted to characterize combustion and exhaust emission of dual-fuel compression-ignition engines with diesel-fuel and CNG [17-21]. A notable problematic feature of dualfuel combustion is its performances trade-off, especially when using small amounts of pilot fuel. It is manifested by a reduction of the NOx-particulates with no change in the total efficiency but it is revealed by an increase of specific energy consumption, cyclic variations, and levels of unburned hydrocarbons and $\mathrm{CO}$ relative to the diesel engine operation. These limitations arise from the fact that the flame cannot propagate fast and far enough within the time available to consume the gaseous-fuel/air mixture [1, 22-23]. Such effects can be attenuated by increasing the gaseous-fuel concentration to allow flame propagation into the combustion chamber, or by taking other actions such as: optimizing the stratification of gaseous fuel admission, heating of the intake charge, optimizing the pilot injection timing, changing the pilot fuel, etc. [24]. To be successful, such implementation requires a detailed knowledge of the sensitivity to these parameters for which dual-fuel operation begins to be favorable. Most of the mentioned experimental investigations were generally performed on single cylinder, direct injection, naturally aspirated research engines, which provide better flexibility of control and economy of testing. On the other hand, fundamental investigations concerning enhanced ignition with a pilot fuel system on gas engines are sparse in the open literature. For instance, few experiments were performed on RCEM to investigate the dual-fuel combustion characteristics of lean natural gas/air mixtures using diesel fuel as ignition source [25-26]. Moreover, these studies were generally performed in low-load operating conditions, avoiding then to draw conclusions on the benefits of dual-fuel combustion when applied in real diesel combustion engines. 
Based on these observations, the objective of the present work aims at exploring the impact of the time sequence of the liquid-fuel injection on auto-ignition of the homogenous charge of methane/air and its impact on the flame propagation in operating conditions similar to diesel engines at partial- and full-load operating conditions. Experiments were performed on an "optical" RCEM, providing a valuable reproduction of various heterogeneous combustion modes and especially operating conditions encountered in diesel engine cycles at partial-load, between -40 and +20 CAD around Top Dead Center (TDC). The RCEM was modified to operate under dual-fuel conditions, while controlling the amount of either diesel or methanegas fuels. The primary fuel is methane, which is ignited by the microinjection of liquid-diesel fuel. The cylinder pressure condition selected in the current study ranges between 90 and 120 bar, corresponding to diesel engine-like conditions at partial-loads. The measurements consisted in studying the effects of the methane/air equivalence ratio, pressure and temperature operating conditions on autoignition, inflammation and flame propagation inside the combustion chamber. To this purpose, various optical measurement techniques were systematically employed as measuring tools. In particular, the study of the pilot liquid-fuel penetration and its consequence on ignition of the premixed charge was accomplished using high-speed optical diagnostics. High-speed Schlieren diagnostic was applied to characterize the diesel spray tip penetration as well as the in-cylinder liquid fuel distribution on dual-fuel ignition. Additionally, high-speed shadowgraphy and $\mathrm{OH}^{*}$ -

chemiluminescence techniques were used to determine ignition delays. Complementary high-speed $\mathrm{OH}^{*}$-chemiluminescence experiments were finally carried out to investigate the effect of fuel injection on the timing sequence of the combustion propagation inside the combustion chamber.

\section{Experimental Apparatus}

The following presentation of the experimental apparatus focuses on two aspects: the RCEM, its operating principle and modes, and the optical diagnostics, their setups and characteristics.

\section{Rapid Compression Expansion Machine}

\section{RCEM Operating Principle}

The operating principle of the RCEM (Figure 1.a) can be separated in two parts presented in Figure 1.b; the experiment area (on the left) and the driving area (on the right).

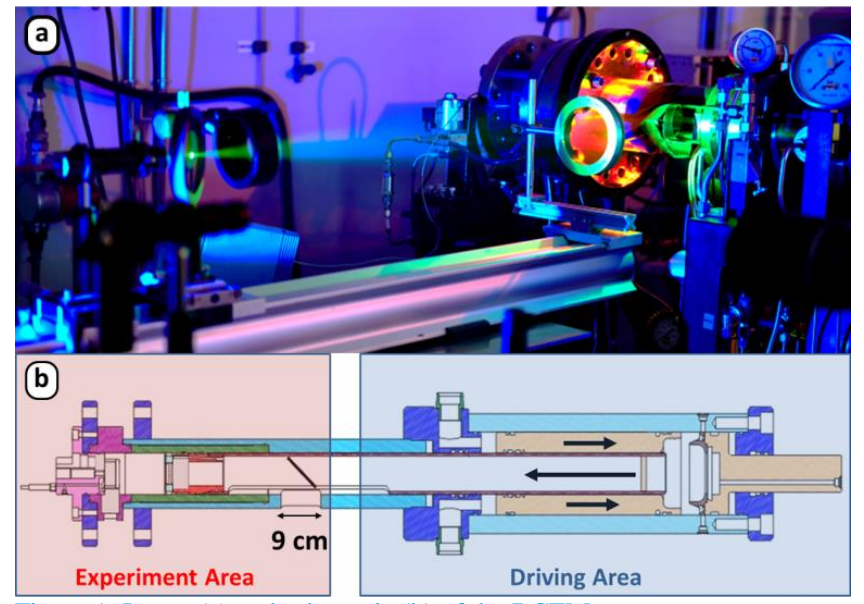

Figure 1. Image (a) and schematic (b) of the RCEM.

Page 2 of 11
The experiment area consists of the liquid-fuelled injector and the combustion chamber enclosed by the cylinder wall and the transparent piston head. This design permits to successfully reproduce the operating conditions of a single cylinder diesel engine [25-27]]. The RCEM sizing specifications are summarized in Table 1. The machine is instrumented to control and adjust the liquid-fuel injection timing and volume, the cylinder pressure, and the piston stroke. The latest is controlled thanks to the driving area. It uses hydraulic and pneumatic chambers coupled with solenoid valves to provide the energy to move the piston. This mode of operation means that the centre of gravity is kept at every position of the piston, guaranteeing a strong acceleration of the piston without any exterior forces and therefore minimizing vibrations of the entire machine. Thus, vibration free operation of the machine favours the use of optical measurement diagnostics with a high reproducibility ratio.

Table 1. RCEM specifications.

\begin{tabular}{|c|l|l|}
\hline Cylinder Volume at BDC & {$\left[\mathrm{cm}^{3}\right]$} & 886 \\
\hline Cylinder Volume at TDC & {$\left[\mathrm{cm}^{3}\right]$} & 27 \\
\hline Piston Diameter & {$[\mathrm{mm}]$} & 84 \\
\hline Piston Stroke & {$[\mathrm{mm}]$} & 160 \\
\hline Combustion Chamber Volume & {$\left[\mathrm{cm}^{3}\right]$} & 913 \\
\hline
\end{tabular}

The RCEM also offers the opportunity to reproduce most different engine states and thermodynamic conditions encountered in conventional diesel engines. Due to its design specially devoted to perform single-shot runs, the RCEM is efficient to suppress the cycle-to-cycle variations of real engines [25-27]. The single-shot mode enables the simulation of full-load operating conditions. Therefore, it can dissociate the fuel evaporation process from the aerodynamics inside the combustion chamber. This is of prime importance to provide a detailed understanding of the physical and chemical processes occurring before and during dual-fuel combustion. The optical access is achieved through an optical window in the bottom of the piston with a diameter, $\mathrm{D}_{\text {visu }}$, of $45 \mathrm{~mm}$ and $16.6 \mathrm{~mm}$ in depth coupled with a $45^{\circ}$ tilted mirror (Figure 2). An additional transparent ring can be placed as an optical cylinder liner to allow the penetration of a laser sheet inside the combustion chamber. The materials of the windows are synthetic quartz glass.

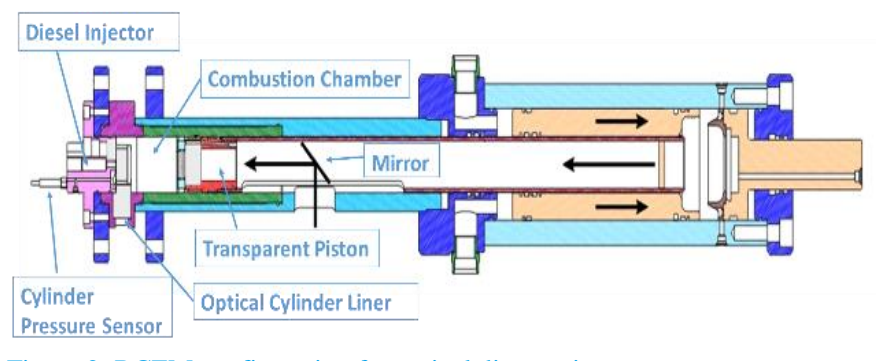

Figure 2. RCEM configuration for optical diagnostics.

Thanks to the single-shot operating mode, the RCEM is more efficient than a "classical" visualization high-pressure test cell to observe and analyze the basic phenomena involved. This is true since the RCEM is able to reproduce the dynamic motion of the piston with a 95\% confidence, as shown in Figure 3. The valid region $(-40-+20$ CAD relative to the TDC) is obtained by comparing the piston stroke of a conventional diesel engine and the one of the RCEM. These results are shown for two operating conditions, 1300 and $2800 \mathrm{rpm}$, which produce compression ratios, $\tau$, of 10 and 25 , respectively. Unlike an optical internal combustion engine, the RCEM allows a maximum pressure around $250 \mathrm{bar}$, permitting high compression ratios, as well as simulating full-load engine conditions. 


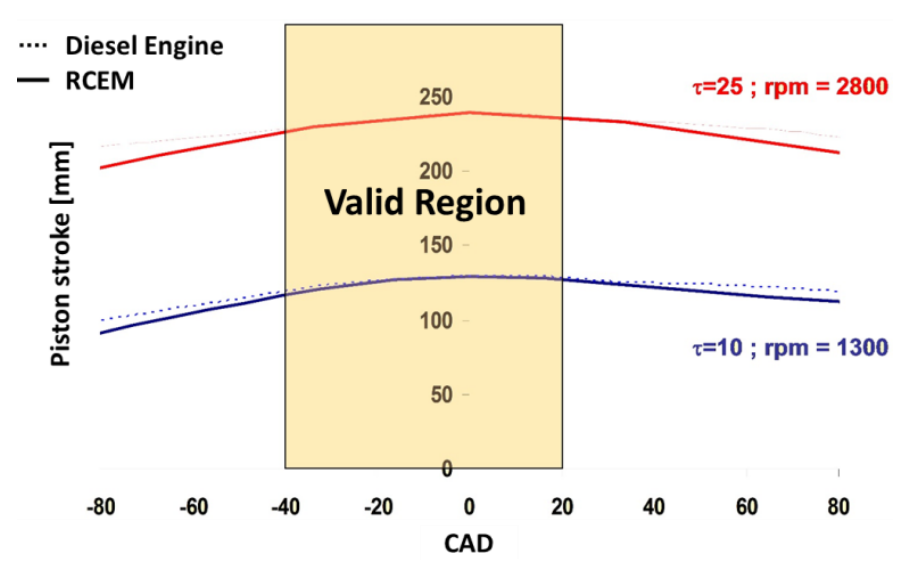

Figure 3. Diesel engine vs. RCEM piston strokes.

Finally, both piston and cylinder walls can be heated up to $493 \mathrm{~K}$ $\left(120^{\circ} \mathrm{C}\right)$ to be representative of real engine conditions. Being originally designed to only test conventional-like injection diesel engines, the RCEM was modified for the current study.

\section{RCEM Modifications for Dual-Fuel Combustion}

The main adaptation the RCEM required to perform dual-fuel combustion took place on the intake air/swirl pipe. It was adapted for to inject the gaseous $\mathrm{CH}_{4}$ inside the combustion chamber. To guarantee perfect mixing between air and $\mathrm{CH}_{4}$, the gaseous fuel is injected straight into the intake pipe that feeds the compression chamber. This modification made necessary to synchronize the dualfuel injection with the operation of the RCEM.

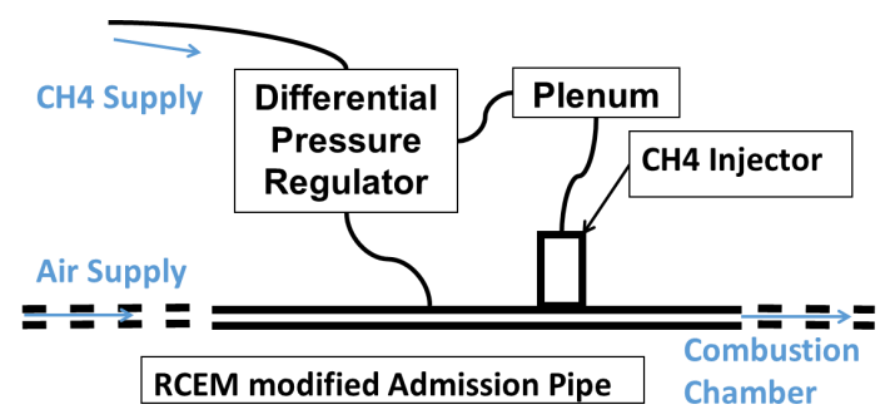

Figure 4. RCEM intake modifications for dual-fuel combustion experiments.

Methane is injected to the combustion chamber by compressed air that supplies the charge gas pressure of the machine. This process assures complete mixing and transportation to the RCEM combustion chamber before the test cycle. The gas is supplied by a high-pressure bottle equipped with a pressure regulator. A plenum is used to feed the $\mathrm{CH}_{4}$ injector to the desired pressure. This system is regulated by a differential pressure regulator system, which combines a Bronkhorst EL-PRESS ${ }^{\circledR}$ pressure meter/controller and a Bronkhorst EL-FLOW ${ }^{\circledR}$ mass flow meter/controller. It supplies the injector with regulated constant pressure above the intake pressure (variable during the intake), as represented in Figure 4.

Intake and exhaust are controlled with respect to the piston stroke, outside of the valid region period. The valves are opened and closed using a specifically developed routine, which ensures that the valves are closed during the experiment. Concerning the exhaust, the valve is open when the piston is at the BDC. Then, air is injected as a purging procedure in order to clean the combustion chamber and reset it for another test.

\section{Optical Diagnostics}

As described earlier, the RCEM allows the use of optical measurements techniques [28] to enhance our understanding of the effect of the Start Of Injection (SOI), and of the equivalence ratio of the charge, $\varphi$, on dual-fuel combustion. It is found that for the diagnosis of the injection and combustion phenomena, a timeresolved sequence of images is of great interest, especially if strong time variation is observed. For this reason, three methods which deliver image sequences at high-repetition rates are considered.

First of all, the Schlieren imaging technique was used to study the time evolution of the pilot liquid fuel injection inside the combustion chamber. Second, the shadowgraph imaging diagnostic was used to analyze the ignition sequence. Third and last, the $\mathrm{OH}^{*}$ -

chemiluminescence imaging technique was implemented to study the ignition sequence and the flame behavior after ignition. This technique offers a comparative and complementary analysis of the phenomena with respect to the widely-used shadowgraph imaging technique.

\section{Schlieren Imaging for Diesel Spray Characterization}

The diagnostic used to visualize the time evolution of the liquid and gaseous diesel fuel penetration inside the combustion chamber was a high-frequency Schlieren system allowing the acquisition of images at a frame rate up to $100 \mathrm{kHz}$.

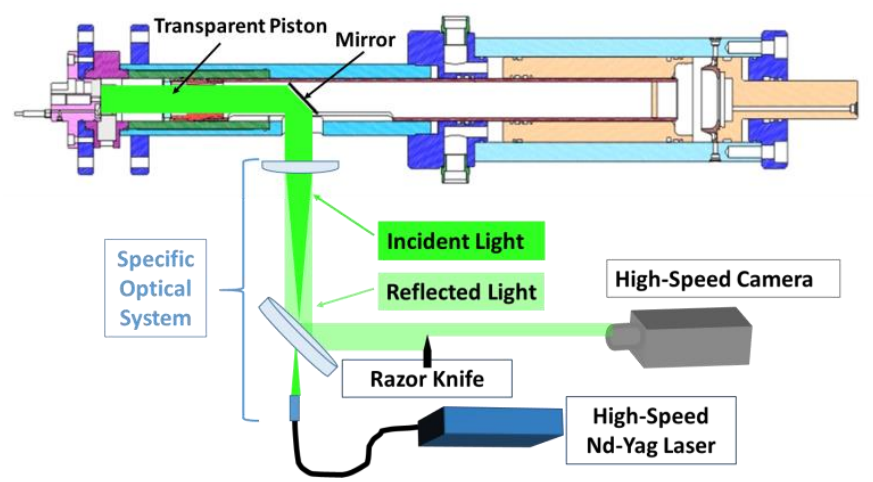

Figure 5. RCEM optical configuration for Schlieren imaging.

The setup shown in Figure 5 uses an Nd-Yag high-speed laser source emitting at a wavelength of $532 \mathrm{~nm}$. The laser beam is routed to the combustion chamber by an optical system specially adapted for this RCEM. The light is reflected on the cylinder head bottom, mirrorpolished for this purpose. This reflected light is passed through a narrow bandpass filter centered at $532 \mathrm{~nm}( \pm 20 \mathrm{~nm})$, and collected with a digital high-speed Phantom v7 video system with an acquisition frequency of $22.1 \mathrm{kHz}$ and a resolution of $288 \times 288$ pix $^{2}$. The bandpass-filter is used to limit the noise from the flame emission and therefore to protect the camera sensor. The laser, camera and injection system are triggered and synchronized with the RCEM microcontroller and delay pulse generators. 

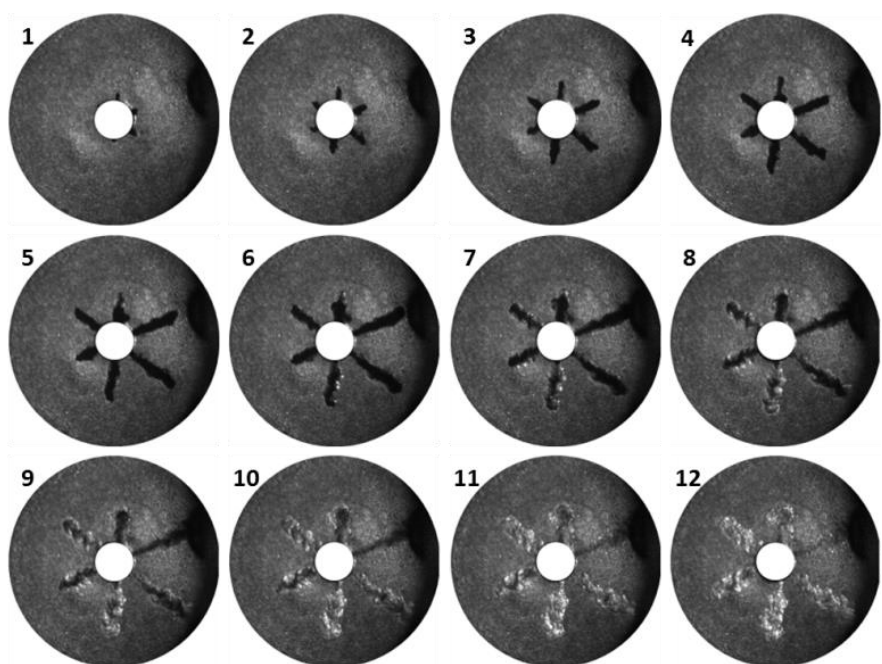

Figure 6. $22.1 \mathrm{kHz}$ diesel injection Schlieren imaging sequence $(\Delta \mathrm{t} \approx 45 \mu \mathrm{s})$; $\mathrm{SOI}=-30 \mathrm{CAD} \& \varphi=0.8 ; \mathrm{D}_{\text {visu }}=45 \mathrm{~mm}$.

Figure 6 illustrates a typical sequence of Schlieren images highlighting the fuel penetration inside the combustion chamber. The white circle at the center of the images is the injector, from which the liquid diesel is exiting. Diesel in its liquid phase is represented in black while the fuel vapor is shown in white.

\section{Shadowgraph Imaging for Ignition Delay Identification}

The shadowgraph imaging technique is an optical diagnostic similar to the Schlieren imaging diagnostic except that it cannot discriminate between liquid and vapor fuel. This diagnostic was used to visualize the time sequence of the autoignition, and therefore to obtain the ignition delay since the start of the pilot diesel-fuel micro-injection. For the experiment, high-speed shadowgraph imaging technique was used. A Spectra-Physics Hg-Xe high power light source $(500 \mathrm{~W})$ was combined with the same digital high-speed Phantom v7 video system and was operated in the same conditions as for the Schlieren imaging technique (Figure 7).

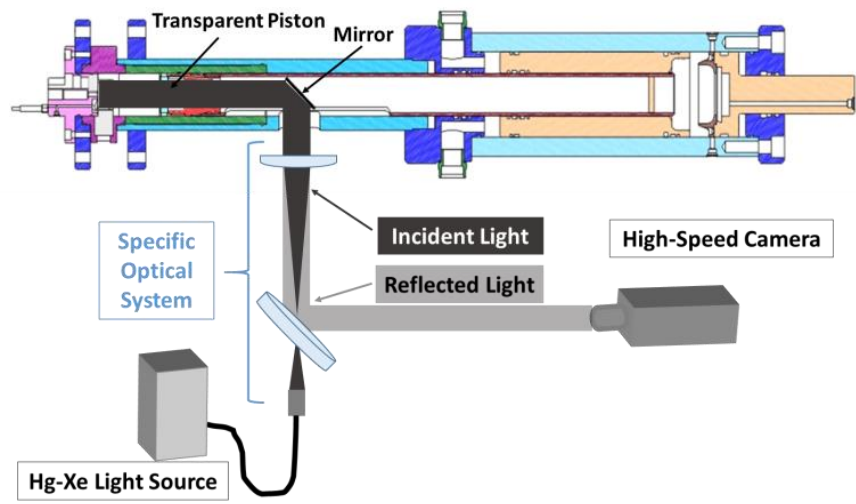

Figure 7. Shadowgraph imaging setup.

For instance, typical shadowgraph images recorded during a run are presented in Figure 8. On the latest, the diesel fuel, in liquid and vapor phases, is shown in black, while the white parts are representative of the combustion zone containing: radicals, combustion products, and soot. Hence, the ignition delay analysis is based on the time difference between the start of injection and the first image in which a white spot, characteristics of ignition, is observed. This diagnostic was only restricted to visualize the autoignition and not the flame propagation because the detection system collects a broadband-light emission induced not only by flame front radicals (like $\mathrm{OH}^{*}$ ) but by all the chemical species and particulates transported in the exhaust gases.

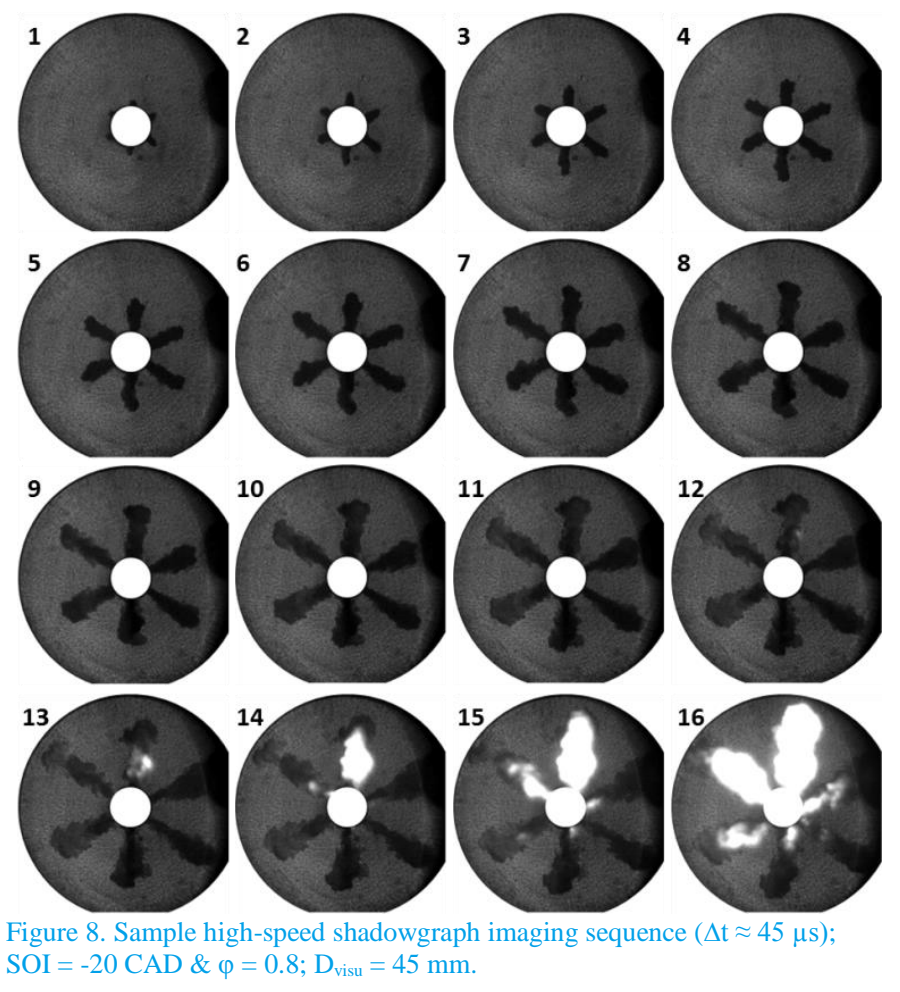

It is important to note that the two aforementioned imaging techniques collect the full light spectrum. Another important observation is the dark spot on the right hand side displayed on the images in Figures 6 and 8, which is only attributed to the presence of the pressure sensor and not to the phenomena observed.

\section{$\mathrm{OH}^{*}$ Chemiluminescence Imaging for Flame Structure and Propagation Analysis}

In hydrocarbon combustion, the $\mathrm{OH}^{*}$, an excited radical, is produced in large quantities in the flame front. This naturally excited radical is largely used in the literature to study the position and the structure of flame in various configurations.

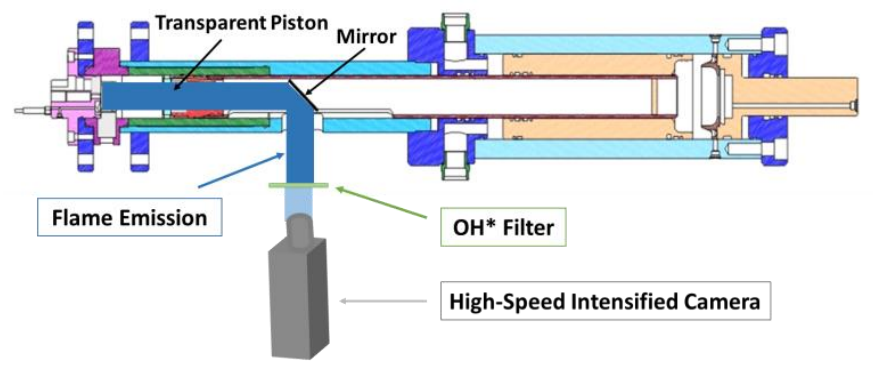

Figure 9. High-speed $\mathrm{OH}^{*}$-chemiluminescence imaging setup.

A high-speed CMOS camera (LaVision HSS8 / Photron Fastcam SA5) coupled with an external image intensifier (Lavision HS-IRO) is used to record the chemiluminescence of $\mathrm{OH}^{*}$. The broadband flame emission collected through the piston window is then filtered through a narrow bandpass-filter (Semrock BrightLine FF01-315/15-

Page 4 of 11 
25), centered at $315 \mathrm{~nm}$ with a bandwidth of $15 \mathrm{~nm}$. The optical filter is placed in front of a $105-\mathrm{mm} \mathrm{f} / 4.5 \mathrm{UV}$ Nikkor lens. The camera was synchronized with the injection trigger pulse and operated at a repetition rate of $15 \mathrm{kHz}$ with a $640 \times 640$ pix $^{2}$ resolution. The IRO intensifier was used with a gate of $1.5 \mu \mathrm{s}$.

\section{Results and Discussion}

The following section is dedicated to the presentation of the methodology used to evaluate the quantity of pilot fuel which will be injected into the combustion chamber of the RCEM during dual-fuel combustion experiments. Thereafter, results on the phenomena observed during dual-fuel experiments such as fuel injection, spray visualization, ignition delay, flame structure, and flame propagation are presented and discussed.

\section{Preliminary study}

To prepare the dual-fuel experiments, investigations were performed to evaluate the minimal quantity of diesel fuel required to solely generate autoignition sites and reduce as much as possible its contribution the global heat released during combustion process.

\section{Definition of Injection}

The injection device selected for dual-fuel experiments is chosen among the devices available on the market and present worldwide on diesel combustion engines. The RCEM is equipped with a 6-hole Bosch common-rail injector placed at the center of the cylinder head. The fuel pump pressure can be varied up to 1600 bar.

This study is centered on apprehending the overall phenomena rather than focusing on characterizing the injection, or the best performances possible. Therefore, resulting data analysis gives values averaged over the 6 fuel sprays.

To perform experiments in the RCEM in engine-like conditions, the pilot diesel-fuel is injected inside the combustion chamber with a reduced injection pressure and injection duration compared to the ones used in conventional diesel engine operations. To inject the smallest amount of pilot fuel, it is necessary to adapt the drive current pulse. In the present study, the high-pressure fuel injector is actuated with a specific current curve in order to comply with the requirement for defined and reproducible fuel-injection processes.

The conventional Engine Control Unit (ECU) is replaced by a power driving module (IPoD Coil Power Driver EFS 8427) on the RCEM. It uses magneto-electric technology to deliver the booster voltage required to bring the current up to a high value as quickly as possible in the booster phase. The opening current is applied for $350 \mu \mathrm{s}$, followed by a $50-\mu$ s holding current. In parallel, the injection pressure is limited to $400 \mathrm{bar}$. After calibration experiments, the diesel injected quantity is measured around $1.4 \mathrm{~mm}^{3}$. This volume is in accordance with the manufacturer data and published data [17].

To evaluate the reproducibility of this diesel-fuel micro-injection, high-speed Schlieren visualizations were performed. The microinjection sequence was performed five times with the cylinder only charged with air. For this preliminary study, the start of injection was fixed at -30 CAD relative to the TDC. The penetration lengths presented in Figure 10 were measured from these tests. These results ensured a $95 \%$ confidence on the reproducibility of liquid fuel injection. The same confidence was observed by analyzing the ignition delays from the same data acquisitions.

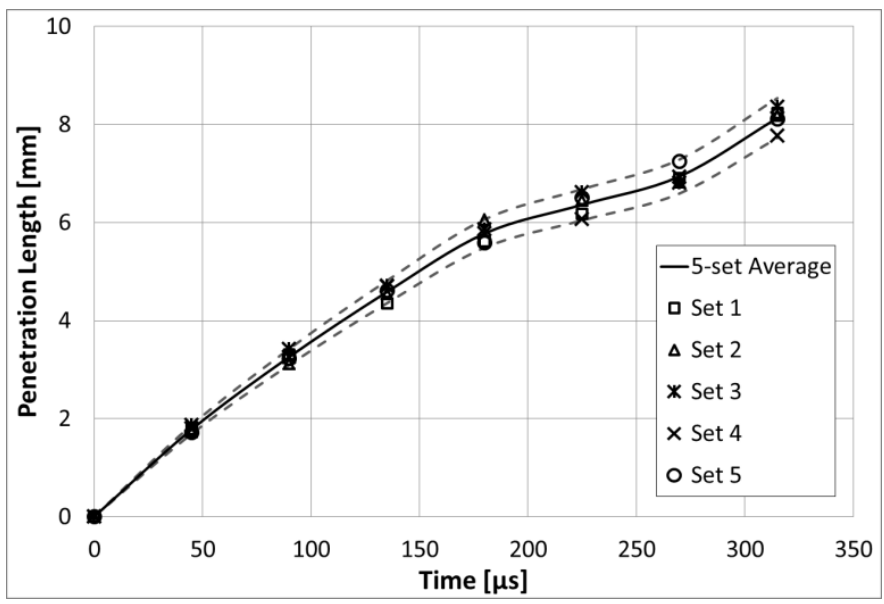

Figure 10. Time evolution of the penetration length of the diesel microinjection in air; $\mathrm{SOI}=-30 \mathrm{CAD} \& \varphi=0$.

Performances of the RCEM are compared between a compression cycle of the charge only with no diesel injection, and a cycle including only the diesel micro-injection. The goal of this comparison is to ensure that the diesel micro-injection is only producing the energy required to ignite the charge, and nothing more, in order to maximize the diesel substitution rate. In the same time, the chargeonly case validates the need of diesel injection for its ignition. In Figure 11 are reported two parameters of interest, the measured cylinder pressure (lines) and the heat release (dashed lines), which is calculated from the cylinder pressure, temperature, and piston displacement data. This figure compares three different cycles: a charge only, in blue (no SOI \& $\varphi=1.0$ ), a diesel micro-injection only, in red (SOI $=-30 \mathrm{CAD} \& \varphi=0$ ), and a dual-fuel, in black (SOI $=-30 \mathrm{CAD} \& \varphi=1.0)$. The result indicates a limited effect of the diesel micro-injection on the RCEM performances, but reveals its importance to ignite the charge.

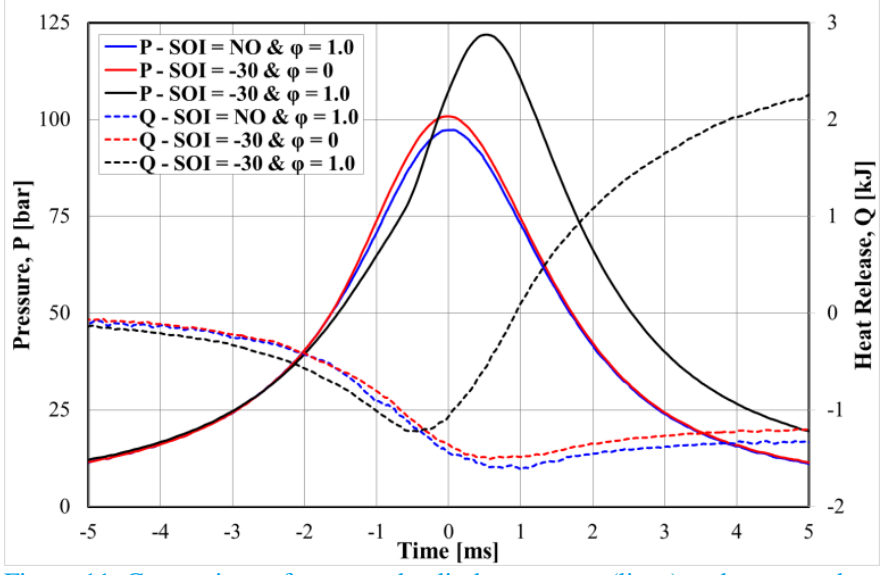

Figure 11. Comparison of measured cylinder pressure (lines) and computed heat release (dashed lines) for three cycles: charge only - blue (no SOI \& $\varphi=$ $1.0)$, diesel micro-injection only - red (SOI $=-30 \mathrm{CAD} \& \varphi=0)$, and dual-fuel black (SOI $=-30 \mathrm{CAD} \& \varphi=1.0)$.

\section{Selection of test cases}

Multiple preliminary tests were performed to verify and ensure the entire apparatus operability range and safety of the RCEM, plus to 
select the test cases to be performed during the dual-fuel experiments. Table 2 summarizes the parameters and variables selected for the RCEM, air, pilot fuel and methane fuel. As shown in Table 2, the equivalence ratio of the methane/air mixture, which is known to be a key parameter in terms of impact on combustion efficiency, was ranged between 0.8 and 1.2. The lower limit of 0.8 is explained by the appearance of knocking possibly linked to the high operating pressure chosen in this study. Significant knocking was observed for lower equivalence ratio, generating heavy stress on the optical RCEM. The upper limit of 1.2 was chosen to provide a global tendency of the equivalence ratio effect around the stoichiometric value. The end goal of the study is to provide an enhanced understanding of the phenomenological processes and not to optimize the engine performances.

Table 2. RCEM, air, and fuel parameters and variables used during the experiments realized for this study.

\begin{tabular}{|l|l|l|}
\hline \multicolumn{3}{|c|}{ RCEM Parameters } \\
\hline Compression Ratio & $16: 1$ \\
\hline Wall Heating Temperature & {$[\mathrm{K}]$} & 363 \\
\hline \multicolumn{3}{|c|}{ Air Parameters } \\
\hline Admission Pressure & {$[\mathrm{bar}]$} & 2 \\
\hline Admission Intake Temperature & {$[\mathrm{K}]$} & 293 \\
\hline \multicolumn{3}{|c|}{ Fuel Parameters } \\
\hline Diesel Injection Pressure & {$[\mathrm{bar}]$} & 400 \\
\hline Diesel Injection Time & {$[\mu \mathrm{s}]$} & 400 \\
\hline Diesel Injection Volume & {$\left[\mathrm{mm}^{3}\right]$} & 1.4 \\
\hline $\mathrm{CH}_{4}$ Injection Pressure & {$[\mathrm{bar}]$} & 2 \\
\hline \multicolumn{3}{|c|}{ Fuel Variables } \\
\hline $\mathrm{Start}^{\mid}$Of Injection & {$[\mathrm{CAD}]$} & $-40,-30,-20$ \\
\hline $\mathrm{CH}_{4} /$ Air Equivalence Ratio & \\
\hline
\end{tabular}

Table 3 displays the operating conditions explored in this study, and the associated diagnostics. Additionally, the oxygen and the methane molar fraction of the charge are presented for each equivalence ratio. Moreover, the cylinder pressure, $\mathrm{P}_{\mathrm{cyl}}$, and the corresponding isentropic-based computation of the temperature, $\mathrm{T}_{\mathrm{isen}}$, are given at the start of the diesel fuel injection (SOI).

Table 3. Study matrix and the diagnostics applied, associated with $\mathrm{CH}_{4}$ and $\mathrm{O}_{2}$ concentration in the charge. ${ }^{*}=$ High-speed Schlieren and shadowgraph imaging. $\mathrm{X}=$ High-speed $\mathrm{OH}^{*}$ chemiluminescence imaging.

\begin{tabular}{|c|c|c|c|c|c|c|c|}
\hline & \multicolumn{4}{|c|}{$\mathrm{CH}_{4} /$ Air Equivalence Ratio } & \multirow{2}{*}{$\begin{array}{c}\mathrm{P}_{\mathrm{cyl}}[\mathrm{bar}] \\
\text { @ SOI }\end{array}$} & \multirow{2}{*}{$\begin{array}{c}T_{\text {isen }}[\mathrm{K}] \\
\text { @ SOI }\end{array}$} \\
\hline & & 0 & 0.8 & 1.0 & 1.2 & & \\
\hline \multirow{3}{*}{$\begin{array}{c}\text { SOI } \\
\text { [CAD] }\end{array}$} & -40 & ${ }^{*} \mathrm{X}$ & * & $* \mathrm{X}$ & * & 20 & 565 \\
\hline & -30 & * $\mathrm{X}$ & $* \mathrm{X}$ & $* \mathrm{X}$ & $* \mathrm{X}$ & 32.5 & 650 \\
\hline & -20 & $* \mathrm{X}$ & * & $* \mathrm{X}$ & $*$ & 55 & 755 \\
\hline \multicolumn{2}{|c|}{$\chi_{\mathrm{CH} 4}[\mathrm{Mol} \%]$} & 0 & 7.7 & 9.5 & 11.2 & & \\
\hline \multicolumn{2}{|c|}{$\chi_{\mathrm{O} 2}[\mathrm{Mol} \%]$} & 20.9 & 19.3 & 19.0 & 18.6 & & \\
\hline
\end{tabular}

\section{Spray Visualization}

The results presented in this section are deduced from the Schlieren images. The data processing of these images were performed with a home-made routine. The first outcome presented in Figures 12 and 13 is the measurement of pilot liquid-fuel penetration length. From the analysis of the luminosity of the spray images, the length of the visible part of the spray was obtained. This length, defined as spray penetration, was assumed to be equal to the distance from the nozzle to the furthest point on the spray axis where the luminosity was above a given threshold. It was assumed that the spray luminosity varies smoothly along the spray, and the effect of cluster shedding from the spray tip was ignored.

Page 6 of 11
The effects of the SOI for an equivalence ratio of 0.8 , and of the equivalence ratio for a $\mathrm{SOI}$ at $-30 \mathrm{CAD}$, are displayed, respectively, in Figures 12 and 13. The lengths of the liquid-fuel penetration into the cylinder are the average values over the six fuel-sprays and over five runs performed for each test case. These averaged values are also fitted using second-order polynomials to show the time evolution tendencies. The SOI characterizes the cylinder conditions (pressure and temperature) at the start of the pilot fuel injection. An observation of the results of Figure 12 shows a decrease of the penetration length as the SOI is closer to the TDC.

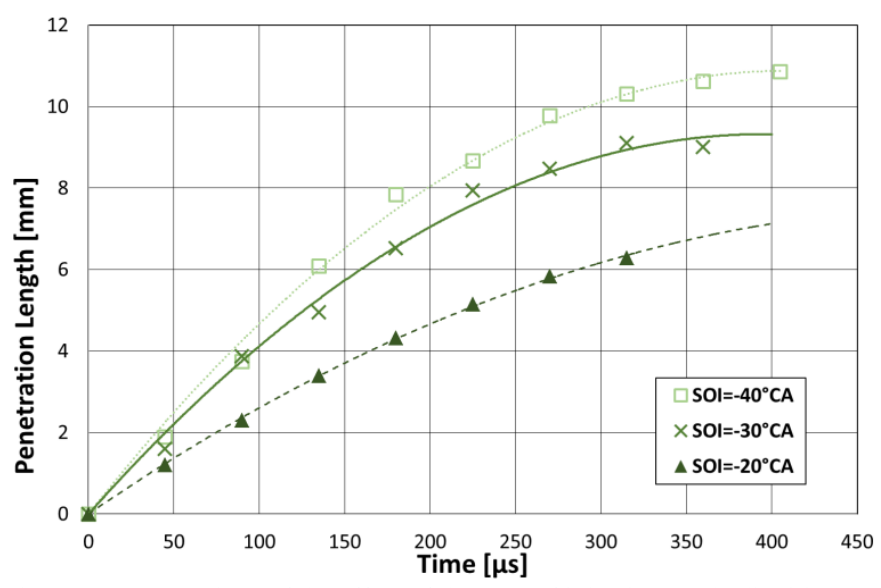

Figure 12. Comparison of the effect of the start of injection on the liquid diesel penetration length analyzed from Schlieren imaging; $\varphi=0.8$.

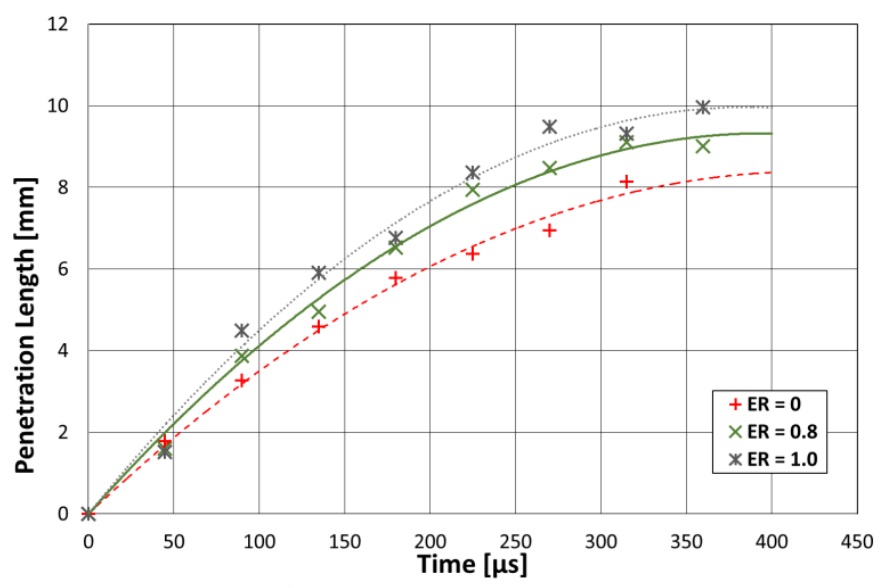

Figure 13. Comparison of the CH4/air equivalence ratio on the liquid diesel penetration length analyzed from Schlieren imaging; SOI = -30 CAD.

Figure 13 presents a similar result as the equivalence ratio is decreasing. In this case, the main change in the cylinder is the charge density, which is increasing as $\varphi$ is decreasing. Both results are corroborating this effect as the cylinder charge pressure, temperature, and density are increasing as the SOI is closer to the TDC. This behavior is consistent with previous studies on liquid-fuel penetration in diesel engine [29-31].

\section{Ignition Delay}

The shadowgraph imaging and the $\mathrm{OH}^{*}$-chemiluminescence imaging techniques were used to measure the ignition delay. Ignition delay is defined as the time interval between the start of injection and the autoignition. In the experiments, the ignition delay was measured based on a method assessing the light intensity variation. Both measurements techniques were used in order to assess their 
comparable nature. The interest of this study focuses only on the ignition delay between the triggered pilot fuel injection and autoignition, for both techniques. Each result is based on a five-run dataset presenting no variation whatsoever in the number of frames between injection and ignition. The results for both techniques are presented in Figure 14. These results uncertainties are respectively $\pm 45 \mu$ s and $\pm 67 \mu$ s for the shadowgraph and the $\mathrm{OH}^{*}$ -

chemiluminescence imaging techniques. These uncertainties come from the delay between two successive images. The representation in bar graphs illustrates both the effect of the fuel injection timing and the equivalence ratio on the variation of ignition delay, obtained from the shadowgraph (left) and the $\mathrm{OH}^{*}$-chemiluminescence (right).

First of all, the $\mathrm{OH}^{*}$-chemiluminescence experiments were not systematically performed for all the twelve test cases because the eight test cases presented in Figure 14 shows excellent agreement with measurements performed with the shadowgraph imaging technique. The small differences between ignition delays measured with both techniques arise from the different repetition rates of images acquisition; $22.1 \mathrm{kHz}$ for shadowgraph imaging against 15 $\mathrm{kHz}$ for $\mathrm{OH}^{*}$ chemiluminescence imaging. The linked bias is around $20 \mu$ s. The results comparison allowed to assess that the $\mathrm{OH}^{*}$ chemiluminescence technique gives comparable results to the ones from the shadowgraph imaging. Therefore, future work could be simplified to implement only the Schlieren and the $\mathrm{OH}^{*}$ chemiluminescence imaging techniques instead of all three. However, this is true if and only if there is no need for precise measurements of this ignition delay. Shadowgraph imaging technique will always be more precise as there is no intensifier required.

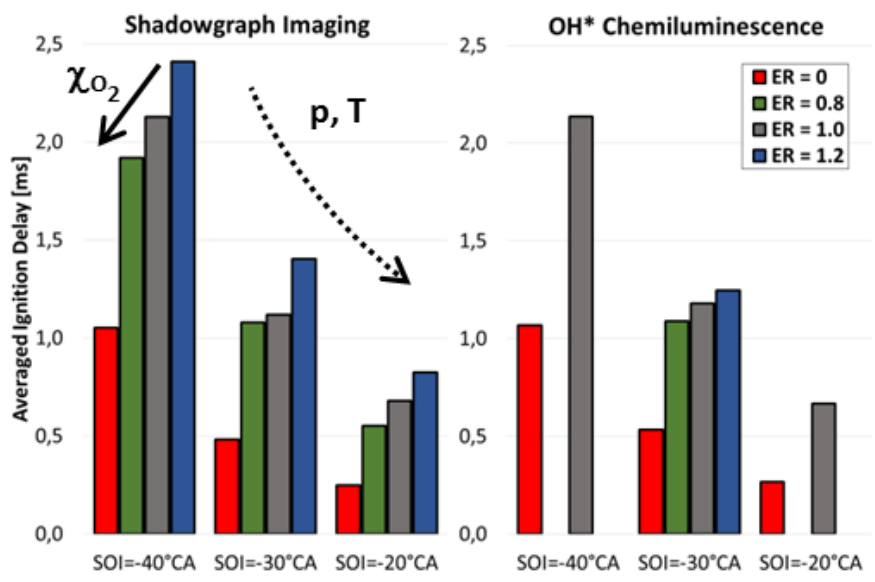

Figure 14. Comparison of ignition delays as a function of the SOI, for various $\varphi$, obtained from shadowgraph imaging (left) and $\mathrm{OH}^{*}$ chemiluminescence (right).

When focusing on analyzing the results for a specific SOI, the emerging observation is that for increasing premixed equivalence ratio, the ignition delay increases as well. Part of the explanation comes from the variation of the oxygen molar concentration, $\chi_{\mathrm{O} 2}$ (cf. Table 3). The increase in oxygen concentration improves the diesel dilution, and therefore decreases the local equivalence ratio toward a faster igniting point.

It is interesting to note that the less oxygen concentration the higher the pressure must be to generate an ignition of the dual-fuel mixture. Finally, focusing on the effect of the injection timing, and therefore looking at a single equivalence ratio, it is observed that the ignition delay decreases as the SOI is closer to the TDC. This result can be correlated to the temperature and pressure increase in the combustion chamber.

\section{Flame Propagation}

The goal of this section is to contribute to a better understanding of the dual-fuel combustion. The main idea is to follow the flame propagation of the burning methane/air mixture, after autoignition by the pilot fuel. Results from the $\mathrm{OH}^{*}$-chemiluminescence imaging are presented hereafter.

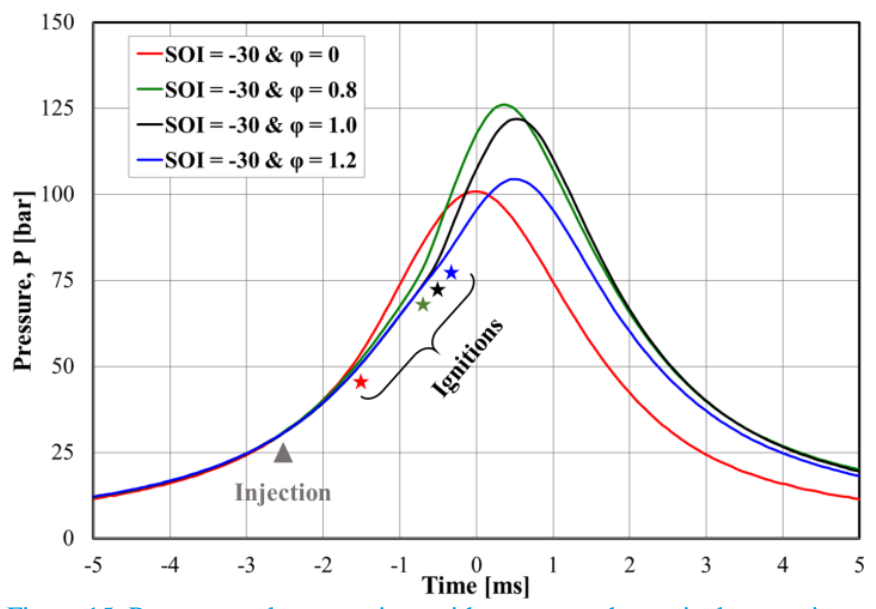

Figure 15. Pressure cycle comparison with respect to the equivalence ratio; SOI $=-30$ CAD \& $\varphi=0,0.8,1.0$, and 1.2 .

In order to visualize the injection and ignition processes along the simulated engine cycle, Figure 15 regroups the cylinder pressure of the dual-fuel cases with the SOI $=-30 \mathrm{CAD}$, and $\varphi=0,0.8,1.0$, and 1.2. In addition, the start of injection and the beginning of the various ignitions are shown. The timeline is centered at the TDC.

The next figures (16-17) show sequences of $\mathrm{OH}^{*}$-chemiluminescence images with a time interval of $200 \mu \mathrm{s}$. This time interval corresponds to the third of the acquisition frequency $(15 \mathrm{kHz})$, meaning that only one out of three instantaneous $\mathrm{OH}^{*}$ images is presented. These sequences display the first $2.4 \mathrm{~ms}$ following the ignition of the premixed charge, which is taken as the time reference. For example, the zero-times, presented Figure 17, correspond to the ignitions shown in Figure 15 for the various premixed equivalence ratio. As a reminder, the $\mathrm{OH}^{*}$ radical is significantly spawned during combustion and is one of the most relevant chemical tracers of the flame front. Hence, the intensity of the $\mathrm{OH}^{*}$ emission is considered proportional to the local heat release produced by combustion. The following results show data with the same color-scale, allowing a direct comparison of the heat release between the different test cases. Finally, it is important to notice the visual illusion produced by the displacement of the diopter, linked to the piston motion. This has the effect of showing a movement of the flame center, due to the position of the tilted $45^{\circ}$-mirror.

Figure 16 shows the comparison of the spatial $\mathrm{OH}^{*}$ chemiluminescence evolution with respect to the SOI for the stoichiometric equivalence ratio, while Figure 17 depicts the effect of the methane/air equivalence ratio on the $\mathrm{OH}^{*}$ distribution for SOI at $30 \mathrm{CAD}$.

As an observation of results displayed in Figure 16, it is possible to note that combustion is more efficient with SOI closer to the TDC.

Page 7 of 11 
The areas of high combustion intensity around the pilot sprays are much wider when SOI is moved closer to the TDC. This effect can be attributed to the cumulative effects of the reduced ignition delay with SOI and larger values of pressure and temperature inside the cylinder. A shorter ignition delay reduces the accumulation of large amounts of evaporated diesel fuel, favoring the sequential ignition of the diesel fuel and methane that is entrained by the pilot spray in the close vicinity of the spray combustion. At the same time, the combined increase of pressure and temperature inside the cylinder leads to an increase in reaction rate, hence leading to a better combustion. charge can be sustained, probably due to low levels of turbulence inside the cylinder which prevent a good entrainment of the hot product gases towards the unburned methane/air mixture. As shown in Figure 17, the reduction of equivalence ratio at a fixed condition of pressure and temperature also increases the combustion efficiency. the fast ignition of diesel fuel and methane surrounding the pilot sprays. Furthermore, the penetration of the fuel sprays in a premixed charge with lower density seems to enhance the inflammation phase as well as the subsequent premixed combustion, resulting in higher $\mathrm{OH}^{*}$ signals over the volume of the combustion chamber. This effect can be attributed to the existence of higher turbulence levels which widely diffuse the hot products of combustion towards the unburned methane/air mixture. It seems also plausible that the flame propagation towards the unburned premixed charge will be dependent of the mixture stratification and in particular the local equivalence ratio distribution around the fuel sprays. Despite favorable conditions, no flame propagation in the premixed As previously observed, the reduction of the ignition delay promotes

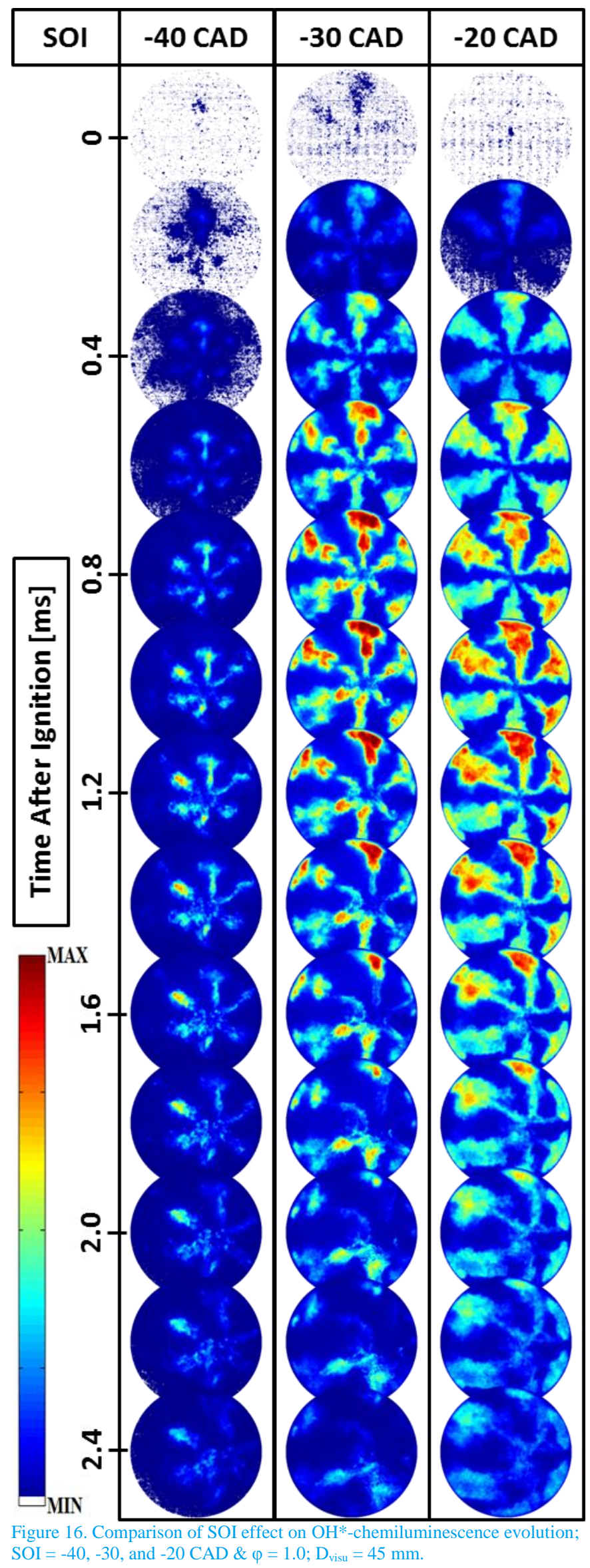

Page 8 of 11 


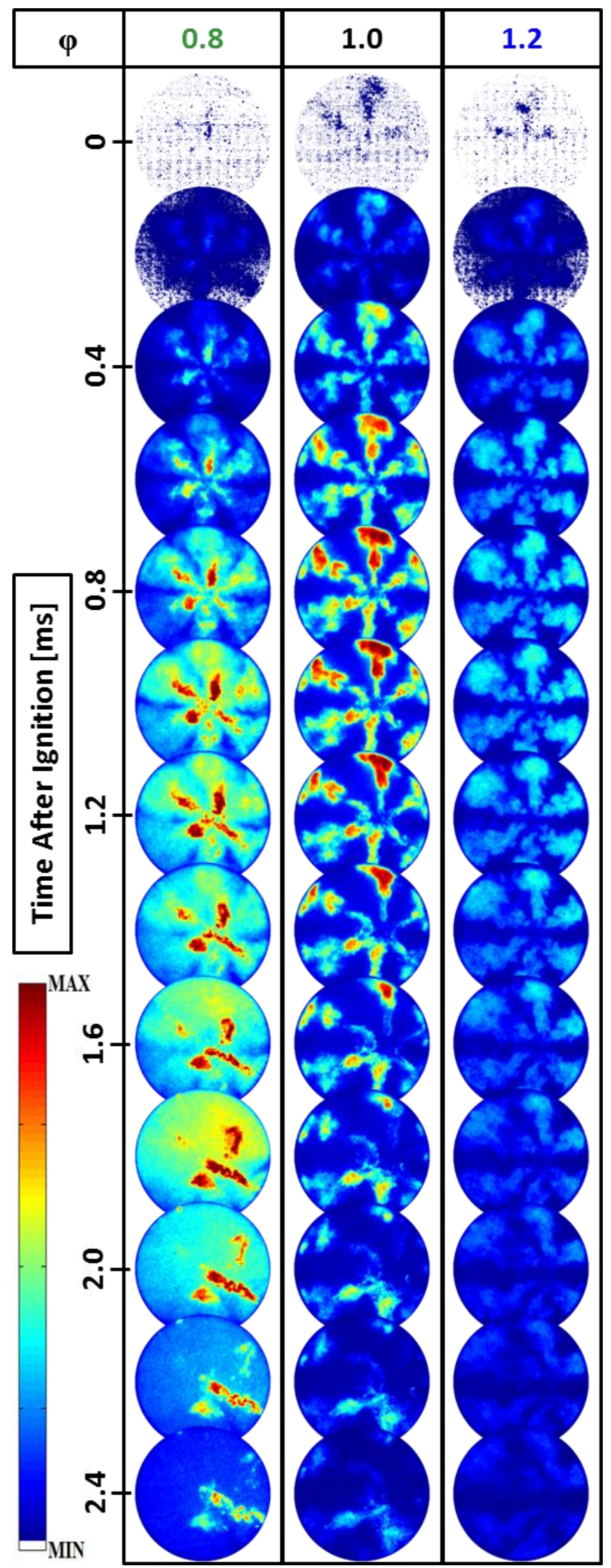

Figure 17. Comparison of $\varphi$ effect on $\mathrm{OH}^{*}$-chemiluminescence evolution; $\mathrm{SOI}=-30 \mathrm{CAD} \& \varphi=0.8,1.0$, and $1.2 ; \mathrm{D}_{\text {visu }}=45 \mathrm{~mm}$.

Page 9 of 11
To gain additional information from the evolution of the flame in the visible part of the combustion chamber, all pixels of each $\mathrm{OH}^{*}$ chemiluminescence image were summed to obtain global sense of the combustion evolution. For instance, the influence of methane/air equivalence ratio is shown in Figure 18. The $\mathrm{OH}^{*}$ signals exhibit reverse behavior; the less there is methane in the cylinder, the higher the $\mathrm{OH}^{*}$ intensity is. This result suggests a strong influence of the premixed phase on the $\mathrm{OH}^{*}$ emission. For high equivalence ratio $(\varphi$ $=1.2$ ), the global $\mathrm{OH}^{*}$ signal shows a one-peak timing evolution spreading on several milliseconds. This evolution is mainly attributed to the heat released by combustion of the six fuel sprays. On the contrary, higher and longer $\mathrm{OH}^{*}$ signal with a two-peak evolution is observed with reducing methane content, demonstrating a longer and better combustion. As shown in Figure 18, this phenomenon is exacerbated for the lowest equivalence ratio investigated, and a net two-peak evolution is clearly visible. The existence of a second peak arises from the development of combustion reactions controlled by the mixing of hot products and the remaining unburned methane/air mixture (visible on Figure 17, . $\varphi=0.8$, at 1.6-1.8 ms).

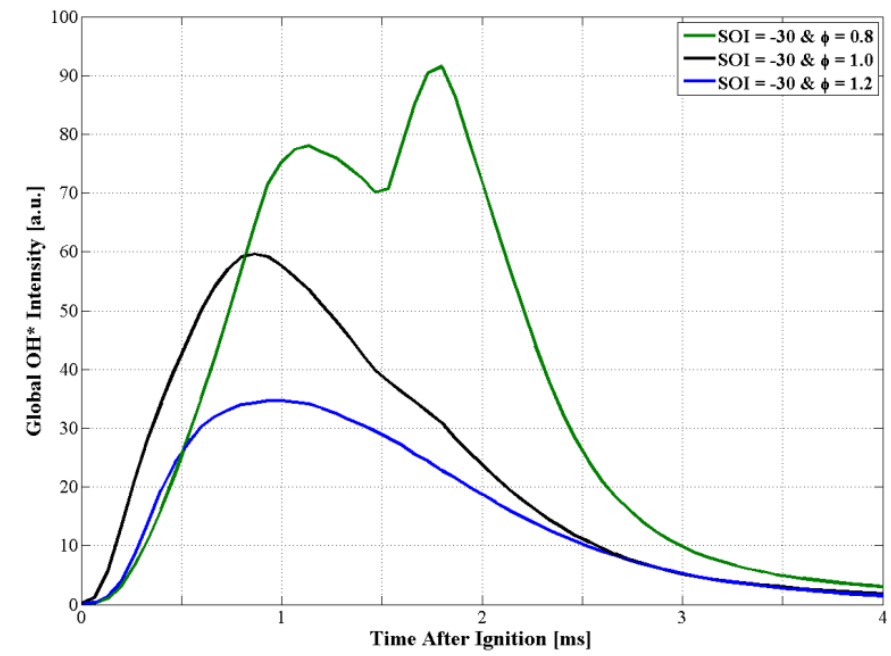

Figure 18. Post-ignition evolution of global $\mathrm{OH}^{*}$-chemiluminescence for the cases presented in Figure 17; SOI $=-30 \mathrm{CAD} \& \varphi=0.8,1.0$, and 1.2.

\section{Conclusions}

An extended experimental investigation was conducted to obtain a deeper understanding of ignition, inflammation and combustion processes occurring in dual-fuel $\mathrm{CNG}$ /diesel combustion systems. The dual-fuel combustion concept consists of burning a homogeneous methane/air charge ignited by a pilot micro-injection of liquid diesel fuel. The operating pressure conditions selected for the current study are ranging between 90 and 120 bar, corresponding to cases of diesel engine at partial-loads. For this purpose, a Rapid Compression Expansion Machine (RCEM) with optical access through the moving piston was modified to operate in the defined conditions without changing its main configurations. Measurements were taken with various advanced high-speed optical diagnostics including Schlieren, shadowgraphy and $\mathrm{OH}^{*}$-chemiluminescence techniques. The measurements consisted of studying the effects of the methane/air equivalence ratio, pressure, and temperature operating conditions on the auto-ignition, inflammation, and flame propagation of the methane/air gaseous charge inside the combustion chamber.

According to the results of this research, the following conclusions can be outlined. 
The short duration adopted to inject the small amount of diesel fuel allows the methane/air charge to ignite and to propagate flames in the combustion chamber for all operating conditions tested. From the $\mathrm{OH}^{*}$ chemiluminescence and shadowgraph imaging, increasing autoignition delay of the pilot diesel spray is observed with decreasing temperature and pressure, independently of the methane/air equivalence ratio. Furthermore, the auto-ignition delay is also significantly reduced in time when the equivalence ratio is reduced.

The work also revealed that the penetration length of the diesel spray tends to be higher when the equivalence ratio is increasing. The same effect is also observed when the SOI is moving away from the TDC. The smaller the gas density, the longer is the penetration length.

These effects (auto-ignition and penetration length) associated with the use of a 6-hole injector produce multi-ignition sites on a large surface area of the combustion chamber, which enhance flame propagation. However, an observation of the time evolution of the spatial $\mathrm{OH}^{*}$ chemiluminescence distribution shows that flame propagation is a function of the gaseous charge. For high-equivalence ratios ( $\varphi=1$ and 1.2), the flame progresses only near the pilot diesel spray region, limiting the consumption of the gaseous methane/air charge. By contrast, the cumulative effect of reducing the ignition delay and decreasing the spray penetration in lower equivalence ratio cases enhances autoignition and flame propagation inside the cylinder. This, along with increasing turbulence generated by the spray penetrating the gaseous charge of lower density, improves mixing of the liquid diesel and the gaseous charge, hence, improving the flame propagation in the full section of the combustion chamber. Increasing the level of turbulence such as the ones encountered in classical combustion engines could then provide major benefits for utilizing the CNG/diesel dual-fuel operating mode.

It is clear that additional work is required to develop the dual-fuel concept, particularly for full-load charge applications. The results presented in this study do not cover all the underlying physical processes governing the dual-fuel combustion. However, they provide a good understanding of the auto-ignition of methane/air mixture by a pilot micro-injection of diesel fuel. Specific experiments need to be conducted in engine-like operating conditions in which local turbulence levels will be higher than the ones used in this experiment. The goal would be to validate the idea that the turbulence will permit the complete burning of the $\mathrm{CH}_{4}$ /air charge. Another important component of these experiments would be to measure pollutants (in situ and ex situ) in order to correlate the results of ignition and flame propagation on the pollutant emissions.

\section{References}

1. Karim G., "Dual fuel Diesel engines," CRC Press, Taylor \& Francis Group, Boca Raton, FL, 2015.

2. Ando H., "Lean burn combustion engines," IMechE Seminar Publications, 1996.

3. Soylu S., "Examination of combustion characteristics and phasing strategies of a natural gas HCCI engine," Energy Convers Management, 46:101-19, 2005, doi:10.1016/j.enconman.2004.02.013.

4. Takashima Y., Tanaka H., Sako T., and Furutani M., "Evaluation of Engine Performance and Combustion in Natural Gas Engine with Pre-Chamber Plug under Lean Burn Conditions," SAE Technical paper 2014-32-0103, 2014, doi:10.4271/2014-32-0103.

Page 10 of 11
5. Weaver C. and Turner H., "Dual fuel natural gas/diesel engines: technology, performance, and emissions". SAE Technical Paper 940548, 1994, doi:10.4271/940548.

6. Gibson C., Polk A., Shoemaker N., Srinivasan K., et al., "Comparison of propane and methane performance and emissions in a turbocharged direct injection dual fuel engine". Trans ASME, J. Eng. Gas Turbines Power; 133 (9):092806, 2011, doi:10.1115/1.4002895.

7. Poonia M., Ramesh A., and Gaur R., "Experimental investigation of the factors affecting the performance of a LPG diesel dual fuel engine," SAE Technical Paper 1999-01-1123, 1999, doi:10.4271/1999-01-1123.

8. Papagiannakis R. and Hountalas D., "Experimental investigation concerning the effect of natural gas percentage on performance and emissions of a DI dual fuel diesel engine," Appl. Thermal Eng., 23: 353-365, 2003, doi:10.1016/j.ijhydene.2013.11.124.

9. Stewart J., Clarke A., and Chen R., "An experimental study of the dual-fuel performance of a small compression ignition diesel engine operating with three gaseous fuels," Proc. IMechE Part D: J Automobile Engineering, 221(8): 943-956, 2007, doi:10.1243/09544070JAUTO458.

10. Abd Alla G., Soliman H., Badr O., and Abd Raboo M. "Effect of pilot fuel quantity on the performance of a dual fuel engine," SAE Technical Paper 1999-01-3597, 1999, doi:10.4271/199901-3597.

11. Lata D. and Misra A. "Analysis of ignition delay period of a dual fuel engine with hydrogen and LPG as secondary Fuels," Int. J. Hydrogen Energy, 36(5): 3746-3756, 2010, doi:10.1016/j.ijhydene.2010.12.075

12. Carlucci A., Laforgia D., Saracino R., and Toto G., "Combustion and emissions control in diesel-methane dual fuel engines: the effects of methane supply method combined with variable in-cylinder charge bulk motion". Energy Conversion Manag., 52(8-9): 3004-3017, 2011, doi:10.1016/j.enconman.2011.04.012.

13. Gatts T., Liu S., Liew C., Ralston B., et al. "An experimental investigation of incomplete combustion of gaseous fuels of a heavy-duty diesel engine supplemented with hydrogen and natural gas," Int. J. Hydrogen Energy, 37(9): 7848-7859, 2012, doi:10.1016/j.ijhydene.2012.01.088

14. Goldsworthy L., "Combustion behaviour of a heavy duty common rail marine diesel engine fumigated with propane," Exp. Thermal Fluid Sci., 42: 93-106, 2012, doi:10.1016/j.expthermflusci.2012.04.016.

15. Kusaka J., Okamoto T., Daisho Y., Kihara R., et al., "Combustion and Exhaust Gas Emission Characteristics of a Diesel Engine Dual-Fueled with Natural Gas", JSAE, Vol. 21, pp. 489-496, 2000, doi:10.1016/S0389-4304(00)00071-0

16. Badr O., Karim G. and Liu B., "An Examination of the Flame Spread Limits in a Dual Fuel Engine", Applied Thermal Engineering, Vol. 19, pp. 107-1080, 1999, doi:10.1016/S13594311(98)00108-2.

17. Dronniou N., Kashdan J., Lecointe B., Sauve K., et al., "Optical Investigation of Dual-fuel CNG/Diesel Combustion Strategies to Reduce CO2 Emissions," SAE Technical Paper 2014-01-1313, 2014, doi:10.4271/2014-01-1313

18. Sahoo B., Sahoo N., and Saha U., "Effect of Engine Parameters and Type of Gaseous Fuel on the Performance of Dual-Fuel Gas diesel Engines - A Critical Review", Renewable and Sustainable Energy Reviews 13, 1151-1184, 2009, doi:10.1016/j.bbr.2011.03.031.

19. Serrano D. and Lecointe B., "Exploring the Potential of Dual Fuel diesel-CNG Combustion for Passenger Car Engine," Proceedings of the FISITA 2012 World Automotive Congress, 2012, doi:10.1007/978-3-642-33777-2_11. 
20. Ishiyama T., Kang J., Ozawa Y., and Sako T., "Improvement of Performance and Reduction of Exhaust Emissions by Pilot-FuelInjection Control in a Lean-Burning Natural-Gas Dual fuel Engine," SAE Int. J. Fuels Lubr. 5(1):243-253, 2011, doi:10.4271/2011-01-1963.

21. Königsson F., Stalhammar P., and Angstrom H., "Characterization and Potential of Dual Fuel Combustion in a Modern Diesel Engine," SAE Technical Paper 2011-01-2223, 2011, doi:10.4271/2011-01-2223.

22. Elliot M. and Davis R., "Dual fuel combustion in diesel engines", Ind. Eng. Chem. 43 2854-2863, 1953, doi:10.1021/ie50504a056

23. Ding X. and Hill P., "Emissions and fuel economy of a prechamber diesel engine with natural gas dual fueling," SAE Technical Paper no. 860069, 1986, doi:10.4271/860069

24. Karim G., "An examination of some measures for improving the performance of gas fueled diesel engines at light load," SAE Technical Paper 912366, Trans. SAE, 1991, doi:10.4271/912366

25. Egúsquiza, J., Braga, S., Braga, C., Villela, A. et al., "Experimental Investigation of the Natural Gas / Diesel DualFuel Combustion Using a Rapid Compression Machine," SAE Technical Paper 2011-36-0360, 2011, doi:10.4271/2011-360360 .

26. Kikusato, A., Fukasawa, H., Nomura, K., Kusaka, J. et al., "A Study on the Characteristics of Natural Gas Combustion at a High Compression Ratio by Using a Rapid Compression and Expansion Machine," SAE Technical Paper 2012-01-1651, 2012, doi:10.4271/2012-01-1651.

27. Schlatter, S., Schneider, B., Wright, Y., and Boulouchos, K., "Experimental Study of Ignition and Combustion Characteristics of a Diesel Pilot Spray in a Lean Premixed Methane/Air Charge using a Rapid Compression Expansion Machine," SAE Technical Paper 2012-01-0825, 2012, doi:10.4271/2012-010825 .

28. Zhao H. "Laser Diagnostics and Optical Measurement Techniques in Internal Combustion Engines". SAE International, Warrendale, PA, 2012, doi:10.4271/R-406.

29. Espey, C. and Dec, J., "The Effect of TDC Temperature and Density on the Liquid-Phase Fuel Penetration in a D. I. Diesel Engine*," SAE Technical Paper 952456, 1995, doi:10.4271/952456.

30. Siebers, D., "Scaling Liquid-Phase Fuel Penetration in Diesel Sprays Based on Mixing-Limited Vaporization," SAE Technical Paper 1999-01-0528, 1999, doi:10.4271/1999-01-0528.

31. Pastor J.V., García-Oliver J.M., Nerva J.-G., and Giménez B., "Fuel effect on the liquid-phase penetration of an evaporating spray under transient diesel-like conditions", Fuel, 90(11), November 2011, pp. 3369-3381, doi:10.1016/j.fuel.2011.05.006.

\section{Acknowledgments}

This work was supported by Institut CARNOT-ESP (Energie et Systèmes de Propulsion) which is gratefully acknowledge.

\section{Abbreviations / Symbols}

\begin{tabular}{|c|c|}
\hline CAD & Crank Angle Degrees \\
\hline $\mathrm{CH}_{4}$ & Methane \\
\hline CI engine & Compression-Ignition engine \\
\hline CNG & Compressed Natural Gas \\
\hline CO & Carbon monoxide \\
\hline $\mathbf{D}_{\text {visu }}$ & Visualization window diameter, in $\mathrm{mm}$ \\
\hline ECU & Engine Control Unit \\
\hline HC & Hydrocarbons \\
\hline $\mathrm{H} / \mathrm{C}$ ratio & Hydrogen/Carbon ratio \\
\hline NOx & Nitrogen oxides \\
\hline $\mathbf{O H}^{*}$ & Hydroxide in its excited state \\
\hline $\mathbf{P}_{\text {cyl }}$ & Cylinder pressure, in bar \\
\hline PLIF & Planar Laser Induced Fluorescence \\
\hline RCEM & Rapid Compression Expansion Machine \\
\hline TDC & Top Dead Center \\
\hline $\mathbf{T}_{\text {isen }}$ & Isentropic computed cylinder temperature, in $\mathrm{K}$ \\
\hline$\varphi$ & $\mathrm{CH}_{4} /$ Air equivalence ratio of the charge \\
\hline$\tau$ & Compression ratio \\
\hline
\end{tabular}

\section{Contact Information}

Pr. Frédéric Grisch UMR 6614 CORIA

Université de Rouen

Site Universitaire du Madrillet - BP 12

FR.76801 Saint Etienne du Rouvray cedex

phone: +33232959784

e-mail: frederic.grisch@coria.fr

www.coria.fr 